\title{
Asthma management: important issues
}

\author{
P. Barnes*, J.C. Virchow ${ }^{\#}$, J. Sanchis ${ }^{\star}$, T. Welte ${ }^{+}$and S. Pedersen ${ }^{\S}$
}

\begin{abstract}
Although most attention has been focused on the drugs used to control asthma, it is increasingly recognised that effective delivery of these drugs to the lungs is just as important. The most effective drugs, $\beta_{2}$-agonists and corticosteroids, are given by inhalation so there has been a search for more efficient inhaler devices that are easier for patients to use. A symposium at the European Respiratory Society Annual Meeting in 2005 discussed some of the important issues in inhaler therapy in adults and children. This article summarises the major points of discussion that arose out of this symposium. New more effective inhaler devices are now becoming available and are likely to have an important impact on asthma management.
\end{abstract}

KEYWORDS: Asthma, dry-powder inhaler, metered-dose inhaler, spacer

D espite the high quality of available medications and treatment regimens that are being simplified on a regular basis, asthma is still not sufficiently controlled in many cases $[1,2]$. Of all asthma patients, $50 \%$ have symptoms on a daily basis and almost all patients report limitations to daily activities [2]. Experts anticipate that advanced inhalers will improve this situation, especially since sweeping innovative medications are not anticipated in the near future.

One of the main issues at the European Respiratory Society conference in Copenhagen in 2005, which was attended by 15,000 experts from around the world, was how to improve asthma management. In guidelines, such as those issued by the Global Initiative for Asthma (GINA), the therapeutic goals are ultimately that the treatment of asthma sufferers should be managed so that they can live as healthy people do, be as free of symptoms and exacerbations as much as possible, have minimal need for reliever medications, have normal lung function and be free of side-effects [3].

Studies such as ACE (Asthma Control and Expectations), which surveyed over 1,000 British asthma sufferers, show that this goal is not being met by a significant percentage of patients [2]. Patient underestimation of their disease severity represents a major problem in asthma management. The ACE study, which was carried out in general practice, revealed the extent of the problem [2], with almost half of patients with typical symptoms of asthma complaining of wheezing, chest tightness, cough and breathlessness (fig. 1a). Even patients who said they felt well were symptomatic, providing evidence that patients underestimate their own symptoms and suggesting that asthma control may be even worse than previously thought (fig. 1a) [2].

\section{PATIENTS DO NOT TALK ABOUT THEIR SYMPTOMS}

Results of the ACE study revealed that asthma symptoms significantly impacted on all aspects of patients' quality of life, including sleep, playing sport, going up and down stairs, walking, socialising, playing with children, going to work and sex life (fig. 1b) [2]. However, surprisingly few patients discussed these lifestyle restrictions with their doctor (fig. 1b) [2]. P. Barnes, of the National Heart and Lung Institute, London, UK, explained how many asthma sufferers do not realise how poorly they are doing. A study by CHETTA et al. [4] examined the relationship between breathlessness perception and clinical and functional features in 36 outpatient asthmatics. They showed that as asthma severity increases from mild to severe, perception of breathlessness, as induced by methacholine challenge, actually worsens (fig. 2) [4]. It seems that the greater the discrepancy between the objective severity of the disease and patients' self-assessment, the worse the pulmonary function is. The reasons for this phenomenon are still unclear.

In contrast, the reasons for poor asthma control are widely known: delayed diagnosis, underdosage, noncompliance and ineffective guidelines [5]. As to the last item, P. Barnes feels that, among other things, the guidelines maybe too complicated and too long $[3,5]$. Furthermore, the question of the best inhaler selection and technique is not addressed regularly [3].
AFFILIATIONS

*National Heart and Lung Institute, Imperial College, London, UK. \#Dept of Pneumology, University Medical Clinic, University of Rostock, Rostock, and

${ }^{+}$Medizinische Hochschule Hannover, Hannover, Germany.

"Hospital Santa Creu i Sant Pau,

Barcelona, Spain.

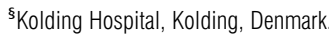

CORRESPONDENCE

P.J. Barnes

Dept of Thoracic Medicine

National Heart \& Lung Institute

Imperial College School of Medicine

Dovehouse Street

London SW3 6LY

UK

Fax: 442073515675

E-mail: p.j.barnes@ic.ac.uk

\section{SUPPORT STATEMENT}

This paper was presented at the "Asthma Management - Important Issues" satellite symposium, Congress of the European Respiratory Society, Copenhagen, Denmark, September 19, 2005. 

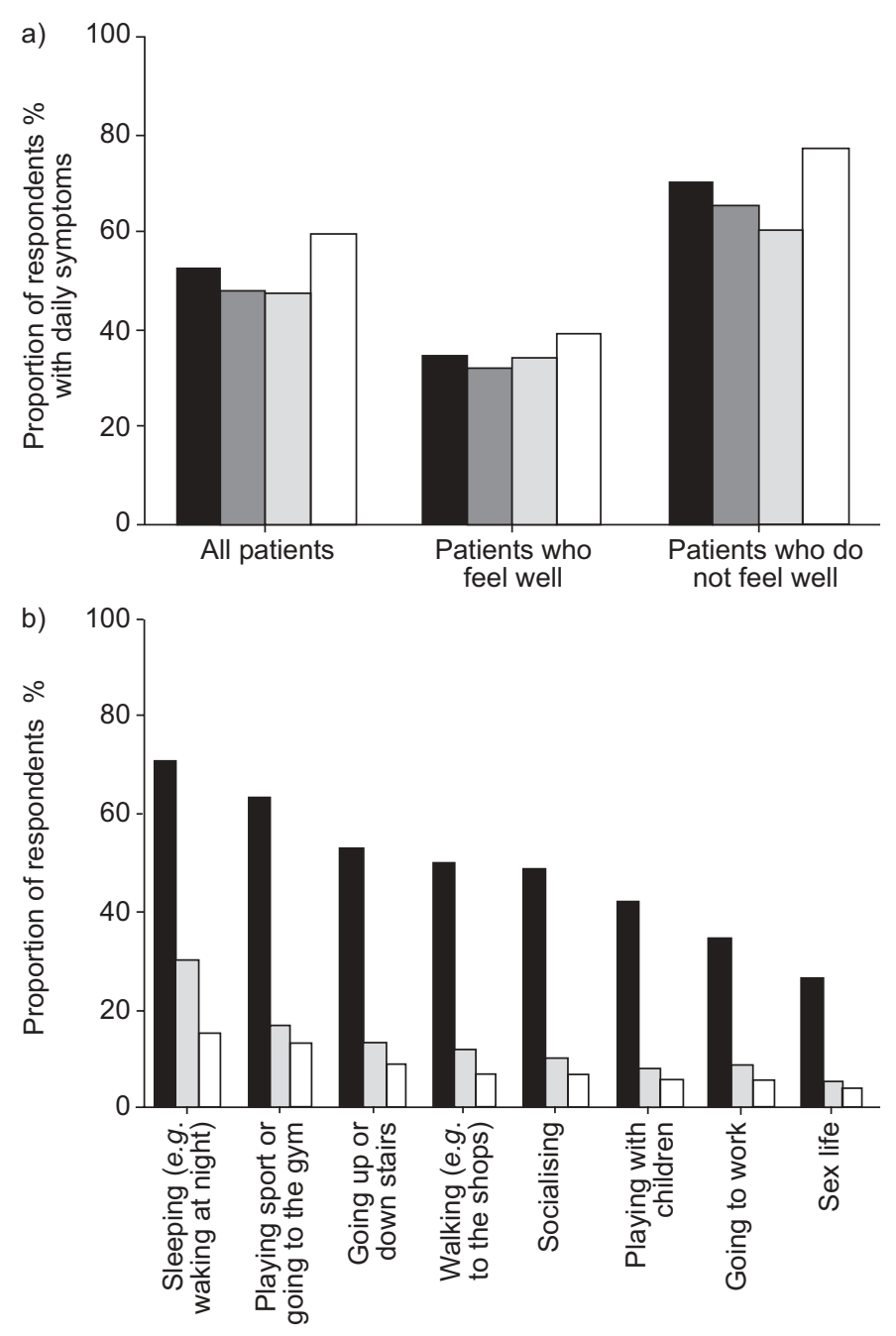

FIGURE 1. Asthma Control and Expectations (ACE study). a) Proportion of respondents $(n=1031)$ with daily asthma symptoms; difference in symptom frequency between patients who report feeling well $(n=415)$ compared with those who report feeling unwell $(\mathrm{n}=472)$. $\mathbf{a}$ : wheeziness; $\mathbf{a}$ : tight chest; $\square$ cough; $\square$ : breathlessness. (b) Restrictions on lifestyle in asthma; proportion of patients who report these limitations. $\mathbf{n}$ : experienced restrictions; 1 : discussed restriction with general practitioner; $\square$ : discussed restriction with practice nurse. Reprinted with permission from GRUFFYDD-JONES [2].

\section{TWELVE PROPOSITIONS FOR BETTER THERAPY}

In the opinion of J.C. Virchow of Rostock University Hospital, Rostock, Germany, joint efforts by specialists and general practitioners are required to advance asthma therapy. He has formulated 12 requirements for supporting this process. 1) The diagnosis must be early and exact, especially the differentiation from other chronic obstructive lung diseases [6]. 2) Early anti-inflammatory therapy is essential because it improves long-term maintenance of lung function [7]. 3) The clinical relevance of guidelines and their effect on the course of the disease should be reconsidered on a regular basis [8-11]. 4) Adequate anti-inflammatory medication should be used to prevent exacerbation [12-14]. 5) The requirement for shortacting relievers must be minimised as far as possible using an effective basic medication [3]. 6) High-risk patients and

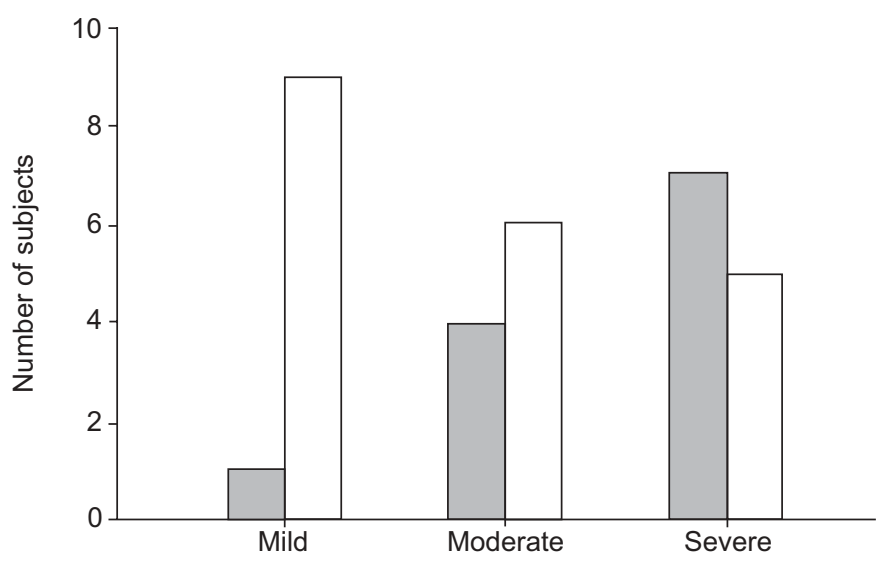

FIGURE 2. Perception of breathlessness as a function of asthma severity with respect to methacholine-induced bronchoconstriction. $\square$ : poor perceivers; $\square$ : good perceivers. Reprinted with permission from CHETTA et al. [4].

population groups at risk should be identified and treated early [15]. 7) Patient care should be improved through cooperation and networks of healthcare providers. 8) Access to diagnostic procedures and therapy must be ensured for patients and persons at risk. 9) Compliance should be improved. The keyword is KISS (Keep It Strictly Simple). Both the treatment regimen and inhaler use should be simple and easy to follow. For example, patients should be prescribed the fewest possible types of medication and, where possible, medication should be delivered in the same inhaler device. The device itself should be as easy to use as possible and incorporate multiple feedback mechanisms which reassure the patient that medication has been delivered and allow compliance checks to be made. 10) The deposition of inhaled pharmaceuticals in the lung must be optimised [16,17]. 11) The inhalers used should be as patient-friendly as possible and combine maximum dose safety with a high level of tolerance to avoid handling errors. If possible, the inhaler, and not individual patient skills, should guarantee correct use [18]. 12) Medication and application must be customised for individual patients. This also means that, ideally, all prescribed medication should be used with the same inhaler so that the patient never has to struggle with different technologies.

\section{INHALER TECHNOLOGY IS THE KEY ISSUE}

The British expert in pulmonology, P. Barnes, is convinced that inhaler technology is the issue that will largely decide if asthma therapy can be successfully improved, since he does not anticipate any breakthroughs with the drugs currently being developed. Anti-immunoglobulin E [19] and tumour necrosis factor- $\alpha$ antibodies [20] will continue to be developed for severe asthma cases; whereas anti-interleukin (IL)-5 and anti-IL-12 have been shown to be ineffective [21]. The oral antiasthmatics currently under development, e.g. PDE4 inhibitors and CCR3 antagonists, appear to have only minor effects and/or have had serious side-effects [22].

Therefore, asthma therapies will continue to rely on the use of established inhaled medications, namely corticosteroids and $\beta_{2}$-agonists, over the next $10-15$ yrs. These therapies can be further developed too, for example by using preparations that 
only have to be administered once a day. Moreover, patientfriendly inhalers should be considered for use, as these are easier to use correctly and give the patient clear feedback about whether the inhalation has been done correctly.

\section{METERED-DOSE INHALERS ARE DIFFICULT FOR CHILDREN TO OPERATE}

S. Pedersen, Department of Paediatrics at the University of South Denmark, Kolding, Denmark, has emphasised that the success or failure of an asthma therapy can hinge on the critically important inhaler technique. Propellant-driven metered-dose aerosols can cause particular problems, especially for paediatric patients. This is mainly due to the fact that they use high pressures at which the active ingredient particles are forced out of the device and hit the throat and soft palate, which causes patients to stop inhaling.

In one study [23], paediatricians investigated the mistakes that children most frequently make when using metered-dose aerosols. 1) They do not exhale before the inhalation. 2) They are not able to coordinate the actuation of the inhaler and the inhalation. This is naturally not an issue with breath-actuated devices. 3) They breathe too quickly, too shallowly or through their noses. 4) They stop inhaling when the spray hits the back of their throats. 5) They forget to hold their breath after the inhalation.

Six out of 10 children made at least one of these mistakes, and thus did not achieve the intended pulmonary deposition of the active ingredient and the desired therapeutic effect [23].

Spacers can help to solve some of these problems because they remedy coordination problems and eliminate the high pressure impaction of drug particles at the back of the throat. However, they are not convenient and are cumbersome to transport, in a school bag, for example. Furthermore, not all children are able to put their lips around the mouthpiece tightly enough, which can result in air leakage. Another problem is that some spacers get electrically charged during cleaning, attracting the active ingredient particles and preventing the full dosage from being delivered.

\section{DRY-POWDER INHALERS CIRCUMVENT COORDINATION PROBLEMS}

An attractive alternative to metered-dose aerosols, either with or without spacers, are dry-powder inhalers (DPIs), such as the Novolizer ${ }_{\circledR}$ (MEDA AB, Solna, Sweden) which eliminate the problem of coordination for patients as they are breath activated. Dry-powder systems use the force of a patient's inspiration to break up the released active-ingredient/releaseagent conglomerate into respirable particles. The amount of force required to do this, i.e. how fast the respiratory flow rate needs to be, varies from device to device.

According to S. Pedersen, the differences between DPIs are considerable. Some dispense a very small but very stable percentage of the particles, regardless of the inhalation rate (fig. 3). The particles are small enough to get into the periphery of the lungs but large enough not to then be exhaled again. For others, the nature of the inspiration has a much greater affect on the number of respirable particles, with the Turbuhaler ${ }^{\circledR}$ (AstraZeneca, Draco, Sweden), for example (fig. 3) [24]. Slow inhalation causes the powder to be released before there is enough respiratory force to effectively break down the conglomerate [24].

Variations in the nature of inspiration are not an issue with the Novolizer ${ }^{\circledR}$. The flow trigger valve system releases powder only after a certain flow rate has been achieved $\left(35 \mathrm{~L} \cdot \mathrm{min}^{-1}\right)$ $[18,25]$. When a flow rate of $35-50 \mathrm{~L} \cdot \mathrm{min}^{-1}$ has been achieved, multiple feedback mechanisms are triggered that signal inhalation is correct at that moment in time (fig. 4). The Novolizer ${ }^{\circledR}$ has a low airflow resistance which, together with the control and feedback mechanisms, makes it ideal for inhalation therapy in children $[26,27]$. Children aged $\geqslant 6$ yrs and even asthma sufferers with severely restricted pulmonary function can easily muster the necessary effort to carry out the inhalation [26].

\section{ADULTS ALSO STRUGGLE WITH METERED-DOSE INHALERS}

P. Barnes also noted that adults find it no easier to use conventional metered-dose inhalers (MDIs) than children. Unless they have been trained, only one in five patients is able to use the spray correctly [28]. After being trained, however, this statistic is still only one in two. In contrast, nearly $90 \%$ of all patients can correctly operate breath-actuated MDIs and DPIs after receiving instructions [28].

Experts demand that the success of the inhalation depends as little as possible on the patient's skill and instead, should be guaranteed as much as possible by the inhaler. According to T. Welte of the Medizinische Hochschule Hannover (Hannover Medical School, Hannover, Germany), the needs of the patients are of the utmost importance. Patients want devices that are easy to operate correctly, provide clear feedback on the success of the inhalation manoeuvre and offer as many inhaled

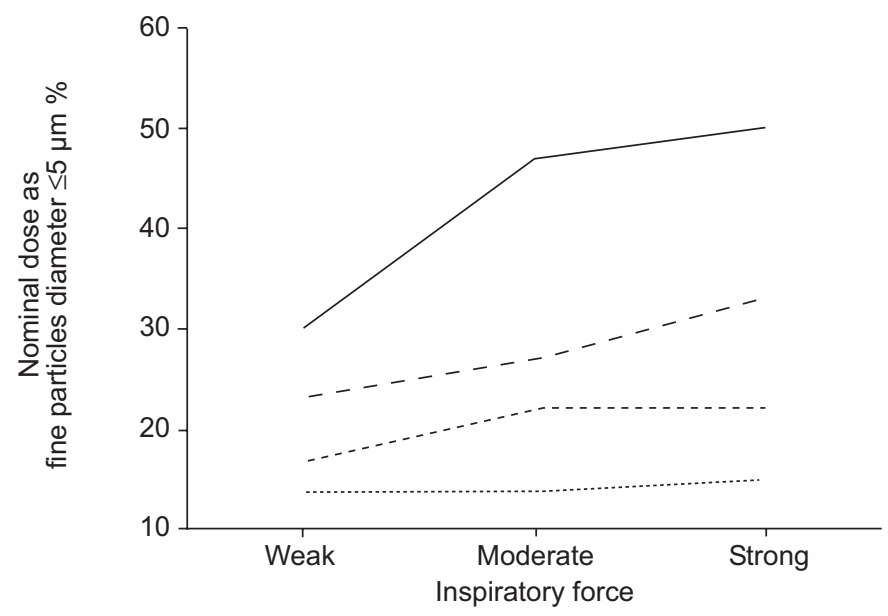

FIGURE 3. Effect of inspiratory rate on respirable particles generated from different inhalation devices. —_: budesonide Turbuhaler $r_{\mathbb{B}}$ (AstraZeneca, Draco, Sweden; 40, 60, $80 \mathrm{~L} \cdot \mathrm{min}^{-1}$ ) [personal communication: Pedersen S., Kolding Hospital, Kolding, Denmark: Problems children have with asthma inhalers. Presented at the "Asthma Management - Important Issues" satellite symposium, Congress of the European Respiratory Society, Copenhagen, Denmark, September 19, 2005]; - - - -: beclomethasone dipropionate Chiesi Inhaler (Chiesi Pharmaceuticals, Parma, Italy; 19, 29, $\left.38 \mathrm{~L} \cdot \mathrm{min}^{-1}\right)$; ------: beclomethasone dipropionate Diskhaler (GlaxoSmithKline, Greenford, UK; 79, 118, $158 \mathrm{~L} \cdot \mathrm{min}^{-1}$ ); ........ Fluticasone Diskhaler (GlaxoSmithKline; 61, 91, $122 \mathrm{~L} \cdot \mathrm{min}^{-1}$ ). 


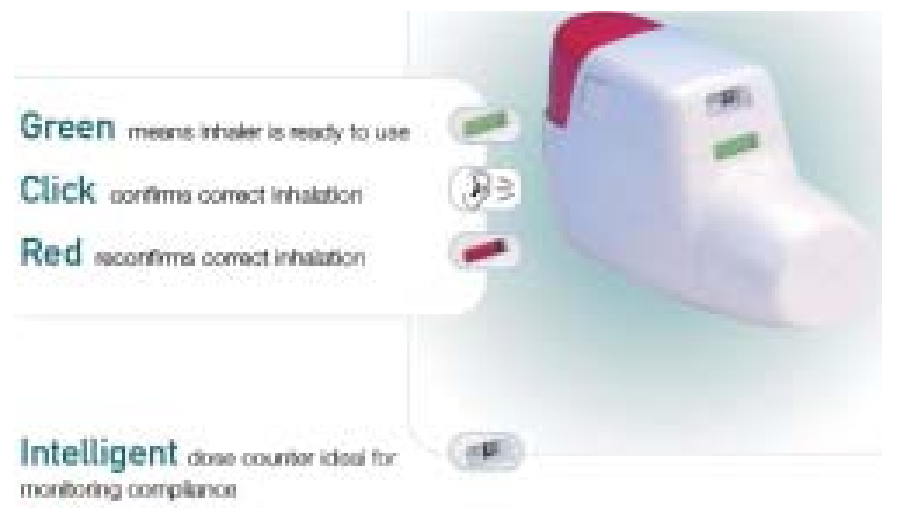

FIGURE 4. Multiple feedback mechanisms of the Novolizer (MEDA AB, Solna, Sweden).

medications as possible in the same inhaler. These features would avoid training patients on how to use a new device for every new medication. The Novolizer ${ }^{\circledR}$ can do all this, as was impressively demonstrated by the pulmonologist.

\section{FEEDBACK MECHANISMS FACILITATE TREATMENT}

Feedback signals, which patients use to determine if they have done the inhalation correctly, are the most important contribution. The Novolizer ${ }_{\circledR}$ has multiple feedback signals which assure and reassure patients and healthcare providers that sufficient drug has been delivered to the lungs (fig. 4): These feedback mechanisms include the following: 1) A visual signal in the form of a colour change in the control window. The colour switches from red to green during loading and then back to red after successful inhalation. 2) An acoustic signal in the form of an audible "click" heard when the inhalation was performed correctly. 3) A taste signal in the form of a sweet taste. 4) An "intelligent" counter that keeps track of the correctly executed inhalations and which can be used by physicians to check compliance.

The Novolizer ${ }^{\circledR}$ also prevents patients from inadvertently overdosing with the preparation because the device cannot be reloaded until the previously loaded dose has been correctly inhaled. The fact that up to 200 doses for reloading are available in the inhaler, without the cartridge having to be replaced, makes it more convenient for patients and more environmentally friendly.

From a pulmonologist's point of view, it is important that a high deposition rate is achieved in the lungs and the periphery of the lungs, and that as little medication as possible deposits in the mouth, throat and gastrointestinal tract. MUNZEL et al. [29] assessed the reliability of dosing through the Novolizer ${ }^{\circledR}$ and the Turbuhaler ${ }^{\circledR}$ both in vitro, by analysis of the fine particle dose (FPD), and in vivo, as shown by lung deposition achieved at different flow rates. They showed that the variability of the FPD (particle size $<5 \mu \mathrm{m}$ ) was lower with the Novolizer ${ }^{\circledR}$ by $34-86 \%$ (fig. 5), as was the variability of the lung deposition $(\mathrm{p}=0.029$ at a comparable targeted flow rate of $60 \mathrm{~L} \cdot \mathrm{min}^{-1}$ ) [29]. These data suggest that the Novolizer ${ }_{\circledast}$ may improve the reliability of inhalation therapy by reducing both the variability of the delivered drug and that of the lung deposition.

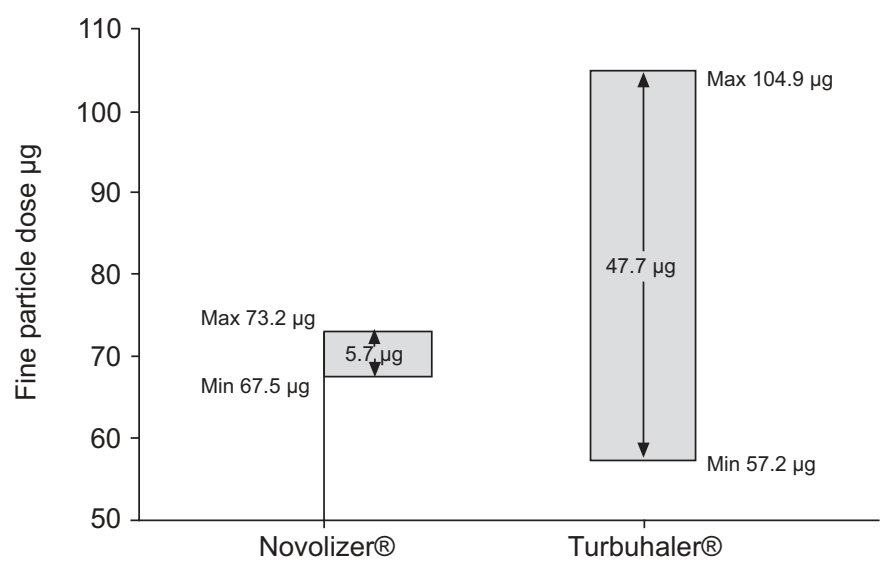

FIGURE 5. Variability of fine particle dose and lung deposition of budesonide delivered through the Novolizer $\mathbb{B}$ (MEDA AB, Solna, Sweden) or Turbuhaler ${ }_{\mathbb{B}}$ (Astra Zeneca, Macclesfield, UK). Reprinted with permission from MunZEL et al. [29]

A comparative scintigraphic study also showed that the Novolizer ${ }_{\circledR}$ achieved more pulmonary deposition and less oral deposition than the Turbuhaler ${ }^{\circledR}$ when both devices were used correctly [16] (fig. 6). Thirteen healthy subjects inhaled a dose of budesonide $(200 \mu \mathrm{g})$ radiolabelled with technetium $99 \mathrm{~m}$, on four randomised occasions, through the Novolizer ${ }_{\circledR}$ at peak inspiratory flow rates of 90,60 and $45 \mathrm{~L} \cdot \mathrm{min}^{-1}$, and through the Turbuhaler ${ }^{\circledR}$ at a peak inspiratory flow rates of $60 \mathrm{~L} \cdot \mathrm{min}^{-1}$ [13]. Results showed that the Novolizer ${ }^{\circledR}$ has a higher lung deposition value averaging $19.9 \%$ of the dose at an inspiratory flow rate of $45 \mathrm{~L} \cdot \mathrm{min}^{-1}$ and up to $32.1 \%$ at $90 \mathrm{~L} \cdot \mathrm{min}^{-1}$ compared with just $21.4 \%$ for the Turbuhaler ${ }^{\circledR}$ at a flow rate of $60 \mathrm{~L} \cdot \mathrm{min}^{-1}$ (fig. 6) [16]. The Novolizer ${ }^{\circ}$ also deposits significantly more budesonide in the lungs than the Turbuhaler ${ }^{\circledR}$, whether used at a comparable peak inspiratory flow rate or with comparable inspiratory effort. Conversely, the Turbuhaler ${ }_{\circledR}$ deposits more drug in the oropharynx (fig. 6) [16].

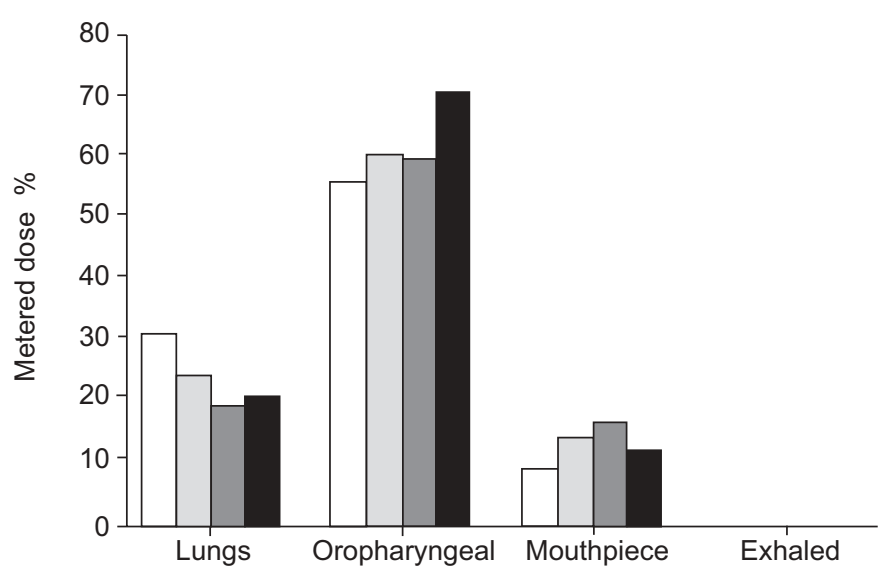

FIGURE 6. Fractionation of the dose from the Novolizer ${ }_{\mathbb{B}}$ (MEDA AB, Solna, Sweden) at peak inhaled flow rates of 90,60 and $45 \mathrm{~L} \cdot \mathrm{min}^{-1}$ compared with data for the Turbuhaler (AstraZeneca, Draco, Sweden) at a peak inhaled flow rate of $60 \mathrm{~L} \cdot \mathrm{min}^{-1}$. Data are expressed as a percentage of the metered dose. $\square$ : Novolizer $_{\circledR}\left(90 \mathrm{~L} \cdot \mathrm{min}^{-1}\right) ; \quad$ : Novolizer ${ }_{\mathbb{B}}\left(60 \mathrm{~L} \cdot \mathrm{min}^{-1}\right) ; \quad$ : Novolizer ${ }_{\circledast}\left(45 \mathrm{~L} \cdot \mathrm{min}^{-1}\right)$; 口: Turbuhaler ${ }_{\circledast}\left(60 \mathrm{~L} \cdot \mathrm{min}^{-1}\right)$. Reprinted with permission from NEWMaN et al. [16]. 


\section{REFERENCES}

1 Rabe K, Vermeire P, Soriano J, Maier W. Clinical management of asthma in 1999: the Asthma Insights and Reality in Europe (AIRE) study. Eur Respir J 2000; 16: 802-807.

2 Gruffydd-Jones K. Measuring pulmonary function in practice. Practitioner 2002; 246: 445-449.

3 Global Initiative for Asthma. Global strategy for asthma management and prevention. NHLI/WHO workshop report. National Institute of Health, National Heart, Lung and Blood Institute. NIH Publication Number 02-3659. Updated October 2004.

4 Chetta A, Gerra G, Foresi A, et al. Personality profiles and breathlessness perception in outpatients with different gradings of asthma. Am J Respir Crit Care Med 1998; 157: 116-122.

5 Barnes PJ. Achieving asthma control. Curr Med Res Opin 2005; 21: Suppl. 4, S5-S9.

6 Tiles SA. Differential diagnosis of adult asthma. Med Clin North Am 2006; 90: 61-76.

7 Selroos O, Lofroos AB, Pietinalho A, Riska H. Asthma control and steroid doses 5 years after early or delayed introduction of inhaled corticosteroids in asthma: a reallife study. Respir Med 2004; 98: 254-262.

8 Veen JC, Smits HH, Ravensbert AJ, Hiemstra PS, Sterk PJ, Bel EH. Impaired perception of dyspnea in patients with severe asthma. Relation to sputum eosinophils. Am J Respir Crit Care Med 1998; 158: 1134-1141.

9 Bateman ED, Boushey HA, Bousquet J, et al. Can guidelinedefined asthma control be achieved: The Gaining Optimal Asthma ControL study. Am J Respir Crit Care Med 2004; 170: 836-844.

10 O'Byrne PM, Bisgaard H, Godard PP, et al. Budesonide/ formoterol combination therapy as both maintenance and reliever medication in asthma. Am J Respir Crit Care Med 2005; 171: 129-136.

11 Paulwels RA, Lofdahl CG, Postma DS, et al. Effect of inhaled formoterol and budesonide on exacerbations of asthma. Formoterol and Corticosteroids Establishing Therapy (FACET) International Study Group. N Engl J Med 1997; 337: 1405-1411.

12 Sont JK, Willems LN, Bel EH, van Krieken JH, Vandenbroucke JP, Sterk PJ. Clinical control and histopathologic outcome of asthma when using airway hyperresponsiveness as an additional guide to long-term treatment. The AMPUL Study Group. Am J Respir Crit Care Med 1999; 159: 1043-1051.

13 Green RH, Brightling CE, McKenna S, et al. Asthma exacerbations and sputum eosinophil counts: a randomised controlled trial. Lancet 2002; 360: 1715-1721.

14 Smith AD, Cowan JO, Brassett KP, Herbison GP, Taylor DR. Use of exhaled nitric oxide measurements to guide treatment in chronic asthma. N Engl J Med 2005; 352: 2163-2173.

15 D'Souza W, Burgess C, Ayson M, Crane J, Pearce N, Beasley R. Trial of a "credit card" asthma self-management plan in a high-risk group of patients with asthma. J Allergy Clin Immunol 1996; 97: 1085-1092.

16 Newman S, Pitcairn G, Hirst $P$, et al. Scintigraphic comparison of budesonide deposition from two dry powder inhalers. Eur Respir J 2000; 16: 178-183.

17 Virchow JC. What plays a role in the choice of inhaler device for asthma therapy? Curr Med Res Opin 2005; 21: Suppl. 4, S19-S25.

18 Kohler D. The Novolizer: overcoming inherent problems of other dry powder inhalers. Respir Med 2004; 98: Suppl. A, S17-S21.

19 Rolinck-Werninghaus C, Wahn U, Hamelmann E. Anti-IgE therapy in allergic asthma. Curr Drug Targets Inflamm Allergy 2005; 4: 551-564.

20 Howarth PH, Babu KS, Arshad HS, et al. Tumour necrosis factor (TNF alpha) as a novel therapeutic target in symptomatic corticosteroids dependent asthma. Thorax 2005; 60: 1012-1018.

21 Jonkers RK, van der Zee JS. Anti-IgE and new immunomodulation-based therapies for allergic asthma. Neth J Med 2005; 63: 121-128.

22 Grootendorst DC, Gauw SA, Benschop N, Sterk PJ, Hiemstra PS, Rabe KF. Efficacy of the novel phosphodiesterase-4 inhibitor BAY 19-8004 on lung function and airway inflammation in asthma and chronic obstructive pulmonary disease (COPD). Pulm Pharmacol Ther 2003; 16: 341-347.

23 Pedersen S, Frost L, Arnfred T. Errors in inhalation technique and efficiency in inhaler use in asthmatic children. Allergy 1986; 41: 118-124.

24 Everard ML, Devadason SG, Le Souef PN. Flow early in the inspiratory manoeuvre affects the aerosol particle size distribution from a Turbuhaler. Respir Med 1997; 91: 624-628.

25 Kohler D. Novolizer: new technology for the management of asthma therapy. Curr Opin Pulm Med 2003; 9: Suppl. 1, S11-S16.

26 Von Berg A, Papageorgiou Saxoni F, Wille S, Carrillo T, Kattamis C, Helms PJ. Asthmatic children generate significantly different peak inspiratory flow rates (PIFR) through two different dry powder inhalers (DPIs). Eur Respir J 2003; 53: 562-567.

27 Vogelberg C, Kremer H, Ellers-Lenz B, et al. Clinical evaluation of the peak inspiratory flow generated by asthmatic children through the Novolizer. Respir Med 2004; 98: 924-931.

28 Lenny J, Innes J, Crompton G. Inappropriate inhaler use: assessment of use and patient preference of seven inhalation devices. Respir Med 2000; 94: 496-500.

29 Munzel U, Marschall K, Fyrnys B, Wedel M. Variability of fine particle dose and lung deposition of budesonide delivered through two multiple dose dry powder inhalers. Curr Med Res Opin 2005; 21: 827-833. 